\title{
As evidências no tratamento farmacológico da endocardite infecciosa: uma revisão de literatura
}

\author{
The evidences of pharmacologic treatment for infective endocarditis: a literature review
}

Las evidencias en el tratamiento farmacológico de endocarditis infecciosa: una revisión de literatura

Eduardo Rocha1, Cecília Farias Figueiredo, Daniela Silva Leite1, Larissa Borges da Costa Kalume $^{1}$, Mariana de Castro Castanheira ${ }^{1}$, Silvia Kelly Jacques Sousa de Assis ${ }^{1}$, Márcia Cristina Monteiro Guimarães ${ }^{1 *}$

\section{RESUMO}

Objetivo: Revisar a antibioticoterapia para Endocardite Infecciosa (EI) e seus principais agentes etiológicos. Revisão Bibliográfica: Todos os pacientes devem receber terapia antimicrobiana que deverá perdurar o tempo necessário para eliminar os microrganismos nas vegetações cardíacas. Como a maioria dos casos de El é causada por bactérias Gram-positivas, a Vancomicina é frequentemente uma escolha empírica apropriada em casos agudos. Considerações finais: Apesar dos estudos tratarem dos mecanismos fisiopatológicos de forma clara, a El continua sendo uma doença de alta morbimortalidade e observa-se efeitos de longo alcance na qualidade de vida dos sobreviventes. Entender os fatores determinantes para etiologia e evolução da doença, baseado em dados epidemiológicos, pode contribuir de maneira significativa para elaborar estratégias de prevenção e seguir o tratamento com o fármaco correto. $O$ presente estudo pode contribuir para o processo de educação dos profissionais de saúde que atuam nessa área, bem como melhorar a formação de uma base de dados consistente sobre o tema.

Palavras-chave: Endocardite, Endocardite bacteriana, Tratamento farmacológico.

\begin{abstract}
Objective: Review antibiotic therapy for Infectious Endocarditis (IE) according to the main etiological agents. Literature review: All patients should receive antimicrobial therapy that misses the time necessary to eliminate microorganisms in cardiac vegetation. Since most cases of IS are cause by Gram-positive bacteria, Vancomycin is often an empirical choice applicable in acute cases. Final considerations: Despite the studies deal with the pathophysiological mechanisms clearly, IS remains a disease with high morbidity and mortality and there are far-reaching effects on the quality of life of survivors. Understanding the determining factors for the etiology and evolution of the disease, based on epidemiological data, can contribute significantly to the development of prevention strategies and to follow the treatment with the correct drug. This study can contribute to the education process of health professionals working in this area, as well as improving the formation of a consistent database on the topic.
\end{abstract}

Keywords: Endocarditis, Endocarditis bacterial, Drug therapy.

\section{RESUMEN}

Objetivo:Revisar la terapia antibiótica para la endocarditis infecciosa (EI) de acuerdo con los principales agentes etiológicos. Revisión bibliográfica: Todos los pacientes deben recibir la terapia antimicrobiana que deberá durar el tiempo necesario para eliminar los microorganismos en las vegetaciones cardíacas. Como la mayoría de los casos de El es causada por bacterias Gram-positivas, la Vancomicina es frecuentemente una elección empírica apropiada en casos agudos. Consideraciones finales: Aunque los estudios abordan claramente los mecanismos fisiopatológicos, la El sigue siendo una enfermedad con alta morbimortalidad y

${ }^{1}$ Centro Universitário Metropolitano da Amazônia (UNIFAMAZ), Belém - Pará. *E-mail: guimarcia@yahoo.com.br 
se observan efectos de largo alcance en la calidad de vida de los sobrevivientes. Comprender los factores determinantes de la etiología y evolución de la enfermedad, basado en datos epidemiológicos, puede contribuir significativamente al desarrollo de estrategias de prevención y seguir el tratamiento con el medicamento correcto. Este estudio puede contribuir al proceso educativo de los profesionales de salud que actúan en esta área, así como a mejorar la formación de una base de datos consistente sobre el tema.

Palabras clave: Endocarditis, Endocarditis bacteriana, Quimioterapia.

\section{INTRODUÇÃO}

A Endocardite Infecciosa (EI) é definida por um foco de infecção no coração, apresentando-se, primordialmente, no endocárdio do coração e nas válvulas cardíacas, podendo ser tanto em válvulas nativas quanto em protéticas (FERRO JM e FONSECA AC, 2014; CAHILL TJ e PRENDERGAST BD, 2016).

Mostra-se como uma patologia com alta variedade etiológica, tais como: Staphylococcus aureus, Streptococcus viridans, Streptococcus epidermidis, Enterococcuse Gram negativos, sendo o Staphylococcus Aureus o organismo com maior destaque em termos de causa, esse mostra-se com alta capacidade de levar a uma forma agressiva da doença, geralmente em populações vulneráveis, idosos e pacientes transplantados (CAHILL TJ, et al., 2017; COELHO APP, et al., 2018).

Existe, também, a classificação em aguda e subaguda. Desse modo, na maior parte das vezes alguns sintomas de anomalia cardíaca são preexistentes. Normalmente, ela afeta as válvulas cardíacas e dessa forma, os sintomas da afecção valvular propriamente dita são percebidos, entretanto, as afecções também podem ser notadas em outros pontos do endocárdio. Alguns dos outros sinais e sintomas da endocardite consistem em: sopro cardíaco, febre, calafrios, sudorese, emagrecimento, inapetência, cefaleias, náuseas e vômitos. (MELO L, et al., 2017).

A epidemiologia da endocardite mudou nos últimos anos. Atualmente, Staphylococcus e Streptococcus combinados causam $80 \%$ dos casos. O Staphylococcus aureus representa de $25 \%$ a $30 \%$ dos casos, enquanto os Staphylococcus coagulase-negativos representam $11 \%$ dos casos. Os Streptococcus, principalmente os Streptococcus do grupo viridans, causam $30 \%$ dos casos, com o Streptococcus gallolyticus (um membro do grupo Streptococcus bovis) envolvido em 20 a $50 \%$ dos casos de Streptococcus. Os Enterococcus, especialmente Enterococcus faecalis, representam cerca de $10 \%$ dos casos (LIESMAN RM, et al., 2017).

Os bacilos gram-negativos representam cerca de $5 \%$ dos casos e incluem os organismos do grupo HACEK (espécies Haemophilus, Aggregatibacter, Cardiobacterium, Eikenella e Kingella) e, menos comumente, bacilos Gram-negativos não-HACEK, como Enterobacteriaceae e Gram não fermentantes bacilos negativos. Os fungos são causas raras de endocardite, sendo as espécies de Candida as mais comuns. Vários organismos incultivos ou desafiadores para o cultivo causam endocardite, os mais comuns são Coxiella burnetii, espécies Bartonella e Tropheryma whipplei (LIESMAN RM, et al., 2017).

O entendimento adequado da epidemiologia da El é fundamental, uma vez que microrganismos podem produzir complicações variadas e exigir diferentes tratamentos e profilaxias (WANG, 2012).

A patogênese se expressa em lesões endoteliais causadas por turbulência do fluxo sanguíneo, ocasionando, assim, a formação de um trombo estéril que pode ser colonizado por bactérias, dessa forma, o trombo se transforma em uma vegetação avascular, o que dificulta o acesso dos antibióticos, tornando a El uma doença de difícil tratamento (SALGADO ÂA, et al., 2013). Dito isso, o tratamento em casos de EI Aguda é empírico, uma vez que o quadro não permite postergações, e consiste no esquema: Oxacilina, Penicilina $G$ cristalina e Gentamicina, os dois últimos medicamentos também são utilizados em casos subagudos (LACERDA MVG, et al., 2003).

Assim, o desenvolvimento da El requer a ocorrência simultânea de vários fatores independentes como alteração da superfície da válvula cardíaca para produzir um local adequeado para fixação bacteriana e 
colonização; bacteremia com um organismo capaz de fixar e colonizar de tecido valvar; e criação de vegetação pelo organismo em proliferação dentro de uma matriz protetora de moléculas séricas (por exemplo, fibrina) e plaquetas (HOLLAND TL, et al., 2016).

Para o tratamento do Staphylococci é necessário que se tenha a distinção se o $\mathrm{S}$. aureus é resistente à meticilina (MRSA) ou suscetível à meticilina (MSSA). Dito isso, antibióticos anti-estafilocócicos $\beta$-lactâmicos (cefazolina e oxacilina) são recomendados sempre que possível para El associado a MSSA, entretanto não são amplamente utilizados no tratamento empírico (HOLLAND TL, et al., 2016; COELHO APP, et al., 2018). Para o MRSA, à vancomicina tem sido historicamente o antibiótico de escolha e continua sendo uma terapia de primeira linha nas diretrizes de tratamento (HOLLAND TL, et al., 2016).

A antibioticoterapia indicada para o Streptococci é um antibiótico $\beta$-lactama (como penicilina, amoxicilina ou ceftriaxona) por 4 semanas, ao adicionar um aminoglicosídeo é possível reduzir o tempo do tratamento pela metade se administrado uma vez ao dia em combinação com ceftriaxona (HOLLAND TL, et al., 2016).

Enquanto a terapia do Enterococci cursou, muito tempo, com a combinação de penicilina com um aminoglicosídeo. Todavia, a toxicidade e a resistência associada aos aminoglicosídeos é preocupante. Dessa forma, a combinação de ampicilina e ceftriaxona pode ser eficaz para a El causada por Enterococcus faecalis suscetível à ampicilina, recomendada para pacientes com resistência a aminoglicosídeos ou nos quais há preocupação com nefrotoxicidade. A El resultante de enterocócico resistente à vancomicina é rara, mas é tratada com linezolide e daptomicina (HOLLAND TL, et al., 2016).

Outros microorganismos como o grupo HACEK (Haemophilus spp., Aggregatibacter spp., Cardiobacterium hominis, Eikenella corrodens e Kingella spp.) devem ser considerados resistentes à ampicilina, sendo tratados com ceftriaxona. A El resultante de bacilos Gram-negativos não HACEK são raras, a terapia normalmente envolve cirurgia cardíaca em conjunto com antibioticoterapia prolongada (HOLLAND TL, et al., 2016).

Mesmo sendo considerada uma patologia rara, com taxa de incidência de três a 9 casos por cada 100 000 pessoa, a El ainda é uma doença que causa preocupação entre os médicos uma vez que apresenta alta morbidade, letalidade e possui uma taxa de mortalidade que não diminui significativamente há 30 anos, apesar do constante avanço clínico de profilaxias, de antibioticoterapias e técnicas cirúrgicas (LACERDA MVG, et al., 2003; SALGADO ÂA, et al., 2013; MELO L, et al., 2017).

O diagnóstico de El requer uma combinação de resultados clínicos, microbiológicos e ecocardiográficos (ŞIMŞEK-YAVUZ, et al., 2020). Todavia, o diagnóstico clássico da El é baseado na hemocultura e na constatação da presença de vegetação no exame ecocardiograma. No entanto, até cerca de $30 \%$ dos casos atualmente são classificados como "prováveis", ou seja, há uma probabilidade intermediária devido a achados inconclusivos dos exames de imagens e de cultura.

Existem algumas explicações para a ocorrência de tal fenômeno, entre elas: dispositivos intracardíacos como a substituição da válvula aórtica transcateter e cardiodesfibriladores implantáveis, que geralmente apresentam ao exame imagens hiperecóicas com dificuldade na distinção com as vegetações, aumento da utilização de antibioticoterapia, podendo ocasionar um resultado falso-negativo no exame de cultura, notável prevalência de germes diferentes da família Streptococcu-Staphylococcus, como Gram-negativos e fungos. (CAHILL TJ, et al., 2017).

Atualmente, a prevalência da Endocardite Infecciosa em doentes sem os fatores de risco clássicos aproxima-se dos $50 \%$. Novas perspectivas têm surgido na abordagem da Endocardite Infecciosa, na tentativa de reduzir a mortalidade elevada que se verifica ainda nesta patologia. As novas recomendações apontam para uma necessidade de início precoce de antibioticoterapia, estratificação dos doentes em grupos de risco, cirurgia valvular precoce e encaminhamento para centros médico-cirúrgicos especializados (THUNY F, et al., 2011; FERRO JM e FONSECA AC, 2014; HOEN B e DUVAL X, 2013; FRANCISCHETTO, O, et al., 2014; MELO L, et al., 2017).

De acordo com o exposto, o objetivo deste estudo foi revisar a epidemiologia da El e a antibioticoterapia atualmente administrada no tratamento. 


\section{REVISÃO BIBLIOGRÁFICA}

A El foi universalmente fatal antes do advento dos antibióticos. A seleção de um regime bactericida apropriado é essencial para alcançar a cura nesta doença (RAJANI R, KLEIN JL, 2020).

Atualmente, o gerenciamento da El normalmente requer uma equipe especializada, incluindo, no mínimo, especialista em doenças infecciosas, cardiologista e cirurgião cardíaco, mostrando-se como um desafio clínico e logístico. A formação e capacitação dessa equipe é de suma importância para otimizar a entrega de serviços de saúde e para tomar decisões antecipadas, apresentando, assim, grande possibilidade de melhorar os resultados clínicos. Todos os pacientes devem receber terapia antimicrobiana, usualmente administrada por via parental em uma infusão intravenosa contínua, e um subconjunto pode se beneficiar de intervenção cirúrgica.

O objetivo principal da terapia antimicrobiana é eliminar a infecção. As várias características das vegetações cardíacas apresentam desafios particulares, incluindo alta densidade bacteriana (também chamada de "efeito inóculo"), taxas lentas de crescimento bacteriano em biofilmes e baixa atividade metabólica de microrganismos. Como resultado, cursos prolongados de terapia parenteral com agentes bactericidas (ou fungicidas) é normalmente necessária (HOLLAND TL, et al., 2016; CAHILL TJ, et al., 2017; SMELTZER SC, BARE BG, 2012).

O tratamento bem-sucedido da El dependerá da antibioticoterapia. A cirurgia poder contribuir através da remoção do material infectado e da drenagem dos abscessos. As defesas do hospedeiro são de pouca ajuda. Esse fato explica o motivo pela qual os regimes bactericidas são mais eficazes do que a terapia bacteriostática, tanto em experimentos com animais quanto em seres humanos.

Os aminoglicosídeos sinergizam com inibidores da parede celular (por exemplo, beta-lactâmicos e glicopeptídeos) para a atividade bactericida e são úteis para encurtar a duração da terapia (por exemplo, estreptococos orais) e erradicação de organismos problemáticos (por exemplo, Enterococcus spp.) (HABIB G, et al., 2015).

Segundo os trabalhos de Baddour LM, et al. (2015) e de Habbib G, et al. (2015), a duração da terapia deve ser o suficiente para eliminar os microrganismos nas vegetações cardíacas. Devido à baixa penetração de antibióticos nessas vegetações e as propriedades bactericidas significativamente lenta de alguns dos medicamentos comumente usados (como a vancomicina), geralmente são necessários ciclos prolongados de antibióticos.

Quando atividade bactericida é rápida, cursos mais curtos podem ser viáveis, como por exemplo a terapia combinada com penicilina ou ceftriaxona e um aminoglicosídeo é sinérgica, dessa forma, permite cursos eficazes com o tempo estimado de apenas duas semanas.

Esse curso de terapia mais curto também pode ser identificado em casos em que a vegetação bacteriana se encontra do lado direito, uma vez que costumam ter densidades bacterianas mais baixas do que as do lado esquerdo.

A duração da terapia antimicrobiana é geralmente calculada a partir do primeiro dia em que o sangue culturas são negativas. As hemoculturas devem ser obtidas a cada 24 a 72 horas até que demonstrem que a infecção da corrente sanguínea desapareceu. Em casos de tecido valvar operatório, se as culturas forem positivas, um curso antimicrobiano completo deve ser considerado após cirurgia cardiovascular (BADDOUR LM, et al., 2015; HABIB G, et al., 2015)

De acordo com Machado SNA (2011), foi possível perceber que nas últimas três décadas documenta-se redução da mortalidade geral, antes com média de $25 \%$ a $30 \%$ para $10 \%$ a $20 \%$, esse índice muito está relacionado com o tratamento farmacológico adequado e a suspeita clínica precoce.

Especificamente, nos casos de Endocardite Infecciosa por Staphylococcus aureus, a redução foi de $50 \%$ a $60 \%$ para $15 \%$ a $30 \%$, o que certamente relaciona-se à moderna abordagem cirúrgica precoce durante a Endocardite Infecciosa ativa. 
Por conta da relativa raridade dos casos de Endocardite Infecciosa e sua variável apresentação clínica, o diagnóstico dessa condição é sempre desafiador e frequentemente necessita de alto grau de suspeita clínica e o tratamento farmacológico entra com uma importância extrema para a melhora do quadro do paciente.

Nesse sentido, o trabalho de Yarlagadda V, et al. (2015) destaca que a ação bactericida da vancomicina resulta principalmente da inibição aprimorada da biossíntese da parede celular, da alteração da permeabilidade da membrana citoplasmática e da síntese do RNA (ácido ribonucleico). Com isso, pode promover uma ação antibacteriana eficiente. No entanto, não é ativa in vitro contra bacilos gram-negativos, micobactérias ou fungos.

De acordo com Bruniera et al., (2015), na administração endovenosa da vancomicina pode ocorrer dor, hipersensibilidade e tromboflebite. Durante ou logo após uma infusão rápida, os pacientes podem vir a apresentar reações anafilactoides, incluindo hipotensão, dispneia, urticária ou prurido, choque e parada cardíaca.

Em uma infusão rápida há liberação de histamina, situação que pode causar a síndrome do homem vermelho que é caracterizada por febre, síncope, taquicardia, hipotensão, prurido na pele, náusea ou vômito, erupção e vermelhidão na parte superior do corpo.

Essas reações são comuns quando a administração é rápida (velocidade de infusão superior a 10 $\mathrm{mg} /$ minuto) e geralmente desaparecem dentro de 20 minutos após término da infusão, mas podem persistir por várias horas.

Segundo Shanson D (2008), ultimamente a amoxicilina tem sido a principal recomendação medicamentosa para a profilaxia da endocardite, isso porque essa droga é melhor absorvida pelo trato gastrointestinal e pode promover níveis sanguíneos mais elevados por uma maior duração.

Esse medicamento vem sendo amplamente utilizado há mais de 35 anos, evidenciando-se segura, uma vez que não existem registros de casos relacionados a reações anafiláticas no uso de doses profiláticas para El.

A Agência Reguladora de Medicamentos e Produtos da Saúde do Reino Unido (MHRA) coletou reações adversas suspeitas dos medicamentos usados e armazenou essas reações da amoxicilina. Desde então, foram registrados oito óbitos relacionados a reações alérgicas, dos quais cinco morreram por via intravenosa, dois morreram por via desconhecida e apenas um morreu por via oral, mas estava relacionado à prevenção de endocardite infecciosa irrelevante.

Certamente a terapia deverá ser direcionada ao microrganismo identificado em hemoculturas ou estudos sorológicos. Enquanto se aguarda os resultados microbiológicos, um tratamento farmacológico empírico pode ser selecionado baseado em dados epidemiológicos e características demográficas. Como a maioria dos casos de El é causada por bactérias Gram-positivas, à vancomicina é frequentemente uma escolha empírica apropriada.

No entanto, outros agentes empíricos também podem ser utilizados com base na microbiologia local e nos padrões de suscetibilidade. De acordo com os autores Gould FK, et al. (2012), Baddour LM, et al. (2015) e Habbib G, et al. (2015), as detalhadas recomendações para o tratamento antimicrobiano de patógenos específicos são abrangentes abordadas em diretrizes recentes de tratamento (Quadro 1). 


\section{Revista Eletrônica Acervo Saúde / Electronic Journal Collection Health| ISSN 2178-2091}

Quadro 1 - Terapia específica para patógenos da Endocardite Infecciosa.

\begin{tabular}{|c|c|c|}
\hline Patógeno & Tratamento farmacológico recomendado & Comentários \\
\hline \multirow{4}{*}{$\begin{array}{c}\text { Streptococcus } \\
\text { viridans e } \\
\text { Streptococcus } \\
\text { bovis sensíveis à } \\
\text { penicilina }\end{array}$} & Penicilina & Os efeitos adversos incluem hipersensibilidade e convulsões \\
\hline & Ceftriaxona & Geralmente bem tolerado e a administração uma vez ao dia pode permitir a terapia ambulatorial \\
\hline & Penicilina (ou ceftriaxona) + gentamicina & $\begin{array}{l}\text { A adição de um aminoglicosídeo permite uma menor duração do tratamento às custas de } \\
\text { potenciais efeitos adversos de aminoglicosídeos (toxicidade renal, vestibular e coclear) }\end{array}$ \\
\hline & Vancomicina & O uso deve ser limitado a pacientes com alergia a penicilina \\
\hline \multirow{2}{*}{$\begin{array}{l}\text { Streptococcus } \\
\text { viridans } \\
\text { intermediários a } \\
\text { penicilina }\end{array}$} & Penicilina (ou ceftriaxona) + gentamicina & 4 semanas de terapia recomendada \\
\hline & Vancomicina & Para pacientes alérgicos à penicilina ou para evitar gentamicina \\
\hline \multirow{5}{*}{$\begin{array}{l}\text { Enterococcus e } \\
\text { Streptococcus } \\
\text { viridans resistentes } \\
\text { a penicilina }\end{array}$} & Penicilina (ou ampicilina) + gentamicina & $\begin{array}{c}\text { Terapia prolongada recomendada para válvulas protéticas e duração prolongada dos sintomas } \\
\text { antes do diagnóstico }\end{array}$ \\
\hline & Ampicilina + ceftriaxona & Favorecido em pacientes com insuficiência renal ou resistência a aminoglicosídeos de alto nível \\
\hline & Vancomicina + gentamicina & Efeito nefrotóxico; papel da gentamicina é incerto \\
\hline & Daptomicina & Para enterococos resistentes vancomicina e penicilina; pode combinar com $\beta$-lactâmicos \\
\hline & Linezolida & $\begin{array}{l}\text { Pode ser usado para enterococos resistentes à vancomicina e penicilina, apesar de eventos } \\
\text { adversos, incluindo supressão medular e neuropatia. }\end{array}$ \\
\hline \multirow{6}{*}{ Staphylococcus } & Nafcilina & $\begin{array}{l}\text { S. aureus sensível à meticilina; efeitos adversos incluem erupção cutânea, intersticial } \\
\text { nefrite }\end{array}$ \\
\hline & Cefazolina & S. aureus sensível à meticilina; mais bem tolerado do que a nafcilina \\
\hline & Vancomicina & S. aureus resistente à meticilina \\
\hline & Nafcilina + gentamicina & $\begin{array}{l}\text { Tratamento de } 2 \text { semanas para usuários de drogas intravenosas com El do lado direito sem } \\
\text { complicação }\end{array}$ \\
\hline & Nafcilina + gentamicina + rifampicina & $\begin{array}{c}\text { Para El de válvula protética; substituir vancomicina pornafcilina em pacientes com S. aureus } \\
\text { resistente à meticilina }\end{array}$ \\
\hline & Daptomicina & $\begin{array}{c}\text { El por S. aureus do lado direito; dados observacionais indicam o uso na El do lado esquerdo; } \\
\text { pode combinar com } \beta \text {-lactâmicos }\end{array}$ \\
\hline \multirow{3}{*}{ HACEK } & Ceftriaxona & Efetivo para cepas produtoras de $\beta$-lactamase \\
\hline & Ampicilina/sulbactam & Para cepas produtoras de $\beta$-lactamase \\
\hline & Ciprofloxacino & Para pacientes intolerantes à terapia com $\beta$-lactâmicos \\
\hline Enterobacteriaceae & $\begin{array}{c}\text { Penicilina de espectro estendido ou } \\
\text { cefalosporina }+ \text { aminoglicosídeo (ou fluoroquinolona) }\end{array}$ & Causa rara de El e pode exigir uma abordagem personalizada dependendo do patógeno \\
\hline $\begin{array}{l}\text { Pseudomonas } \\
\text { aeruginosa }\end{array}$ & $\begin{array}{c}\text { B-lactâmicos anti-pseudomonas (como ticarcilina, } \\
\text { piperacilina, } \\
\text { ceftazidima, cefepima ou imipenem) + tobramicina (ou } \\
\text { fluoroquinolona) }\end{array}$ & Geralmente requer terapia prolongada e cirurgia valvar \\
\hline Fungos & $\begin{array}{c}\text { Agente antifúngico parenteral (mais comumente um } \\
\text { produto de anfotericina) }\end{array}$ & Terapia supressora a longo prazo com um agente antifúngico oral é frequentemente necessária \\
\hline
\end{tabular}

Fonte: HOLLAND TL, et al., 2012.

REAS / EJCH | Vol.12(11) | e4464 | DOI: https://doi.org/10.25248/reas.e4464.2020 Página 6 de 9 
De acordo com Gould FK, et al. (2012), a taxa de cura com os esquemas recomendados contra Streptococcus suscetíveis é estimada em $95 \%$. Em casos não complicados, a terapia de curto prazo de duas semanas pode ser administrada combinando penicilina ou ceftriaxona com gentamicina (HOLLAND TL, et al., 2012).

Habbib G, et al. (2015) relataram que os bacilos Gram-negativos HACEK são organismos complexos, crescem lentamente e os testes de concentração inibitória mínima (CIM) podem ser difíceis de interpretação. Relataram também que alguns bacilos do grupo HACEK produzem beta-lactamases e a ampicilina não é mais a opção de primeira linha. Por outro lado, eles são suscetíveis à ceftriaxona, outras cefalosporinas de terceira geração e quinolonas.

No estudo de Tedoldi CL et al. (2009), a escolha do antibiótico para tratamento de Endocardite Infecciosa para mulheres durante a gravidez dependerá da hemocultura e do antibiograma da paciente, visando manter as condições gerais da paciente, eliminar o agente etiológico e evitar os efeitos adversos, a etiologia deve ser suspeitada a partir do sítio clínico acometido, o que inclui: lesões de pele, infecções do trato urinário ou uso de drogas intravenosas ilícitas. É apontado como a principal causa de El durante a gestação, a infecção estreptocócica.

De forma frequente, os casos agudos estão relacionados com os agentes Staphilococcus aureus, Streptococcus pneumoniae e Streptococcus pyogenes, enquanto que o Streptococcus viridans é identificado em casos subagudos. (TEDOLDI CL, et al., 2009). Ademais, os autores Gould FK, et al. (2012), Baddour LM, et al. (2015) e Habbib G, et al. (2015) referem ainda que para Endocardite Infecciosa Valvar Nativa (EIVN), a duração do tratamento varia de 2 a 6 semanas, enquanto uma duração de tratamento de 6 semanas é geralmente usada para Endocardite Infecciosa de Válvulas Protéticas (EIVP). Os antibióticos para EIVN e PVIE são normalmente os mesmos, com exceção da EIVP estafilocócica, para o qual a adição de rifampicina e gentamicina é recomendada.

De acordo com estudo de Tattevin $P$ et al. (2014), os fungos são mais frequentemente observados na EIVP, na El de usuários de drogas intravenosas e em pacientes imunocomprometidos. Gould FK, et al. (2012) relataram que a mortalidade é alta e o tratamento requer administração antifúngica combinada além da substituição da válvula cirúrgica.

A terapia antifúngica para El por Candida inclui anfotericina B lipossômica (ou outras formulações lipídicas) com ou sem flucitosina ou equinocandina; e para a El por Aspergillus, o voriconazol é o medicamento de escolha e alguns especialistas recomendam a adição de equinocandina ou anfotericina $B$ (TATTEVIN P, et al., 2014). Habbib $G$ et al. (2015) recomenda o tratamento supressivo a longo prazo com azóis orais, às vezes por toda a vida.

Em suma, Baddour LM, et al. (2010) e Athan E, et al. (2012) referem que infecções de dispositivos eletrônicos implantáveis cardíacos (como, por exemplo, marca-passos e desfibriladores) pode ocorrer tanto com quanto sem o El valvar associado. Dessa forma, independentemente de infecção parecer envolver apenas o chumbo do dispositivo (que às vezes é chamado de "endocardite por chumbo"), ou a válvula sozinha, ou ambas, é recomendada a remoção completa do dispositivo e do chumbo. Também é recomendado uma antibioticoterapia com os mesmos medicamentos para a El valvar, para tratar a endocardite por chumbo, com duração média de 4 a 6 semanas.

De acordo com Hoppen GR, et al. (2011), além do tratamento de antibioticoterapia também pode ser indicado o tratamento cirúrgico da $\mathrm{El}$, de modo que é de extrema importância entender que essas indicações são semelhantes e podem ser agrupadas da seguinte forma: insuficiência cardíaca grave e progressiva, refratária ao tratamento clínico; infecção não controlada com tratamento antimicrobiano; infecção complicada em prótese valvular cardíaca e embolias arteriais sistêmicas.

Chien $S$ et al., (2019) relataram um caso incomum de endocardite por Finegoldia magna (conhecida como Peptostreptococcus magnus) posteriormente a substituição da válvula cardíaca bioprotética. Após a antibioticoterapia intravenosa inicial e reabordagem cirúrgica para substituição da válvula aórtica protética, o paciente foi transferido com sucesso para a monoterapia com antibióticos orais em um curso de oito semanas de tratamento e recebeu alta com sucesso do acompanhamento cirúrgico. 
O tratamento da El não complicada pode ser gerenciado localmente com comunicação regular junto a equipe especializada na El em um centro de referência. No entanto, o tratamento da El complicada, com insuficiência cardíaca, insuficiência grave de válvula, destruição estrutural (abscesso, perfuração ou formação de fístula) e complicações embólicas ou neurológicas, deve ser gerenciado por uma equipe especializada em El. No centro de referência, todos os casos de El devem ser discutidos regularmente para determinar a terapia antimicrobiana ideal e sua duração; os requisitos e o tempo; ou intervenção cirúrgica e o tipo de acompanhamento necessário (RAJANI R, KLEIN JL, 2020).

\section{CONSIDERAÇÕES FINAIS}

É importante entender que novas formas de atuação têm emergido e proporcionado resultados positivos no combate da El com o sentido de acelerar o processo de diagnóstico, estratificar o risco para diminuição do atraso no início do tratamento com o antibiótico e melhorar as recomendações cirúrgicas e suas técnicas. O entendimento dos fatores determinantes para etiologia e evolução da Endocardite Infecciosa, baseado em dados epidemiológicos e características demográficas, pode contribuir de maneira significativa para elaborar estratégias de prevenção dessa doença e reduzir o impacto na qualidade de vida dos sobreviventes. Realça-se também a posição favorável do profissional de saúde no seguimento destes doentes, por meio do conhecimento dos fatores de risco de cada doente e da manutenção de um contato frequente que permite seguir de perto a evolução do quadro clínico. O presente estudo pode contribuir para o processo de educação dos profissionais de saúde que atuam nessa área, bem como melhorar a formação de uma base de dados consistente sobre o tema abordado.

\section{REFERÊNCIAS}

1. ATHAN E, et al. Clinical characteristics and outcome of infective endocarditis involving implantable cardiac devices. Jama, 2012; 307: 1727-1735.

2. BADDOUR LM, et al. Infective Endocarditis in Adults: Diagnosis, Antimicrobial Therapy, and Management of Complications: A Scientific Statement for Healthcare Professionals From the American Heart Association. Circulation. 2015;132:1435-1486.

3. BADDOUR LM, et al. Update on cardiovascular implantable electronic device infections and their management: a scientific statement from the American Heart Association. Circulation. 2010;121:458-477.

4. BRUNIERA FR, et al. The use of vancomycin with its therapeutic and adverse effects: a review. Eur Rev Med Pharmacol Sci, 2015; 19 (4): 694- 700.

5. CAHILL TJ, PRENDERGAST BD. Infective endocarditis. Lancet, 2016; 387: 882-893.

6. CAHILL TJ, et al. Challenges in Infective Endocarditis. Journal of the American College of Cardiology, 2017; 69: 325-344.

7. CHIEN S, et al. The novel use of oral antibiotic monotherapy in prosthetic valve endocarditis caused by Finegoldia magna: a case study. J Cardiothorac Surg. 2019;14(1):170

8. COELHO AAP, et al. Tratamento da endocardite infecciosa com troca valvar. Revista Caderno de Medicina, 2018; 1:5-12.

9. FERRO JM, FONSECA AC. Infective endocarditis. Handbook of clinical neurology, 2014; 119: 75-91.

10. FRANCISCHETTO $O$, et al. Healthcare-associated infective endocarditis: a case series in a referral hospital from 2006 to 2011. Arquivos Brasileiros de Cardiologia, 2014; 103: 292-298.

11. GOULD FK, et al. Guidelines for the diagnosis and antibiotic treatment of endocarditis in adults: a report of the Working Party of the British Society for Antimicrobial Chemotherapy. The Journal of antimicrobial chemotherapy, 2012;67:269-289.

12. HABIB G, et al. Guidelines for the management of infective endocarditis: The Task Force for the Management of Infective Endocarditis of the European Society of Cardiology (ESC). Eur Heart J, 2015;36:3075-3128.

13. HOEN B, DUVAL X. Infective endocarditis. N Engl J Med, 2013; 368:1425-1433.

14. HOLLAND TL, et al. Infective endocarditis. Nat Rev Dis Primers, 2016;2: 1-22.

15. HOPPEN GR, et al. Tratamento cirúrgico da endocardite infecciosa. Revista Brasileira Cirurgia Cardiovascular. v. 10, n. 4, p. 175- 179, 2011.

16. LACERDA MVG, et al. Manual de Rotinas da Fundação de Medicina Tropical do Amazonas. Manaus: Fundação de Medicina Tropical do Amazonas (FMT/IMT-AM), 2003; 200 p.

17. LIESMAN RM, et al. Laboratory Diagnosis of Infective Endocarditis. J Clin Microbiol, 2017;55:2599-2608.

18. MACHADO SNA. Endocardite Infecciosa - Clínica Integrada I. Campina Grande, 2011.

19. MELO L, et al. Endocardite Infecciosa: Casuística do Departamento de Medicina Interna de um Hospital. Medicina Interna, 2017; 24: 19-23.

20. RAJANI R, KLEIN JL. Infective endocarditis: A contemporary update. Clin Med (Lond). 2020;20(1):31-35.

21. SALGADO ÂA, et al. endocardite infecciosa: o que mudou na última década? Revista HUPE, 2013;12:100-109. 
22. SHANSON D. New British and American guidelines for the antibiotic prophylaxis of infective endocarditis: do the changes make sense? A critical review. Curr Opin Infect Dis, 2008;21:191-199.

23. ŞIMSEK-YAVUZ S, et al. "Consensus Report on Diagnosis, Treatment and Prevention of Infective Endocarditis by Turkish Society of Cardiovascular Surgery (TSCVS), Turkish Society of Clinical Microbiology and Infectious Diseases (KLIMIK), Turkish Society of Cardiology (TSC), Turkish Society of Nuclear Medicine (TSNM), Turkish Society of Radiology (TSR), Turkish Dental Association (TDA) and Federation of Turkish Pathology Societies (TURKPATH) Cardiovascular System Study Group." Turk gogus kalp damar cerrahisi dergisi, 2020; 28,1:2-42.

24. SMELTZER SC, BARE BG. Brunner \& Suddarth: Tratado de Enfermagem Médico Cirúrgica. 12 ed. Rio de Janeiro: Guanabara Koogan, 2012.

25. TATTEVIN P, et al. Fungal endocarditis: current challenges. Int J Antimicrob Agents 2014;44:290-294.

26. TEDOLDI CL, et al. Diretriz da Sociedade Brasileira de Cardiologia para Gravidez na Mulher Portadora de Cardiopatia. Arq Bras Cardiol, 2009;93:110-178.

27. THUNY F, et al.The timing of surgery influences mortality and morbidity in adults with severe complicated infective endocarditis: a propensity analysis. Eur Heart J, 2011; 32: 2027- 2033.

28. YARLAGADDA V, et al. Membrane Disruption and Enhanced Inhibition of Cell-Wall Biosynthesis: A Synergistic Approach to Tackle Vancomycin-Resistant Bacteria. Angew Chem Int Ed Engl, 2015; 9;13644-13649.

29. WANG A. The changing epidemiology of infective endocarditis: the paradox of prophylaxis in the current and future eras. J Am Coll Cardiol, 2012; 59: 1977-1978. 